\title{
Pengaruh Customer Relationship Management (CRM) dan Word of Mouth (WOM) Terhadap Kinerja Usaha Pada Usaha Kecil Menengah di Kota Kediri
}

\author{
Afif Nur Rahmadi ${ }^{1}$ \\ Muhammad Dian Ruhamak ${ }^{2}$ \\ Fakultas Ekonomi Universitas Kadiri \\ Kediri, Jawa Timur Indonesia \\ afifnur@unik-kediri.ac.id ; dianru@unik-kediri.ac.id
}

\begin{abstract}
This study discusses Customer Relationship Management (CRM) and Word of Mouth (WOM) on business performance. Where the population and sample in this study are SMEs in the City of Kediri. Of the types of businesses that become respondents, most of them are processing, trading, transportation and services industries. While the sample of this study amounted to 100 respondents. The technique of determining the sample was purposive sampling where this study was not carried out by all objects but focused on the target. From the results of data analysis and conclusions can be drawn that Customer Relationship Management (CRM) and Word of Mouth (WOM) occur partially on business performance in SMEs in the City of Kediri. In addition, it was found that Customer Relationship Management (CRM) and simultaneously have a significant effect on business performance in SMEs in the City of Kediri.
\end{abstract}

Keywords: Customer Relationship Management (CRM), Word of Mouth (WOM) and Company Performance.

\begin{abstract}
Abstrak
Penelitian ini membahas tentang pengaruh Customer Relationship Management (CRM) dan Word of Mouth (WOM) terhadap kinerja usaha. Dimana populasi dan sampel di penelitian ini adalah UKM di Kota Kediri. Dari jenis usaha yang menjadi responden disini sebagian besar adalah industri pengolahan, perdagangan, transportasi dan jasa-jasa. Sedangkan sampel penelitian ini sejumlah 100 responden. Teknik penentuan sampel digunakan adalah purposive sampling dimana penelitian ini tidak dilakukan seluruh populasi tapi terfokus pada target. Dari hasil analisis data dan pembahasan dapat ditarik kesimpulan bahwa Customer Relationship Management (CRM) dan Word of Mouth (WOM) berpengaruh secara parsial terhadap kinerja usaha pada UKM di Kota Kediri. Selain itu ditemukan bahwa Customer Relationship Management (CRM) dan secara simultan berpengaruh signifikan terhadap kinerja usaha pada UKM di Kota Kediri.
\end{abstract}

Kata kunci : Customer Relationship Management (CRM), Word of Mouth (WOM) dan Kinerja Perusahaan.

\section{PENDAHULUAN}

Dalam perkembangan dunia usaha saat ini, persaingan dunia bisnis sangat tinggi. Ini bisa diketahui banyaknya perusahaan yang gulung tikar karena kinerja usahanya menurun dan banyaknya bermunculan usaha baru. Oleh sebab itu, setiap perusahaan harus 
terus beradaptasi dengan perubahan yang terus berjalan dan bertahan dalam persaingan bisnis yang semakin ketat. Selain itu, banyak perguruan tinggi di Indonesia yang mengajarkan mata kuliah kewirausahaan. Seiring dengan kemajuan tersebut dan semakin banyaknya pelanggan yang berpendidikan tinggi menjadikan pelanggan semakin kritis dan pemilih terhadap produk atau jasa yang akan digunakannya. Mengandalkan produk yang dihasilkan saja tidak akan cukup, perusahaan juga harus memiliki strategi untuk menjalin hubungan baik dan berkelanjutan dengan setiap pelanggannya (Yosua, Suharyono, \& Yulianto, 2017). Hubungan perusahaan dengan pelanggan saat ini selalu menjadi fokus utama untuk terus dijaga dan ditingkatkan oleh perusahaan selain produk yang dihasilkan. Hubungan dengan pelanggan tidak sekedar berupa komunikasi saja. "Bagi sebagian besar perusahaan, pertanyaannya adalah bukan berkomunikasi, tetapi apa yang harus dikatakan, kepada siapa dan seberapa sering" (Kotler, 2003).

Selain menjaga hubungan dengan pelanggan dan calon pelanggan untuk meningkatkan kinerja usaha. Perusahaan juga memperhitungkan komunikasinya dengan pelanggan. Apabila perusahaan menjalin hubungan komunikasi pelanggan yang baik, maka pelanggan itu akan merasa bahwa pealanggan merasa diperhatikan. Oleh sebab itu dalam latar belakang diatas maka hubungan pelanggan dan komunikasi dengan pelanggan dianggap penting.

\section{Tujuan Penelitian}

Tujuan dari penelitian ini adalah untuk mengetahui dan menganalisis pengaruh Customer Relationship Management (CRM) dan Word of Mouth (WOM) terhadap kinerja usaha pada usaha kecil menengah di kota kediri.

\section{TINJAUAN PUSTAKA}

\section{Pengertian Customer Relationship Management}

Tujuan utama CRM adalah untuk meningkatkan pertumbuhan dan profitabilitas jangka panjang melalui pemahaman yang lebih baik tentang perilaku pelanggan. "CRM bertujuan untuk memberikan umpan balik yang lebih efektif dan peningkatan integrasi untuk lebih mengukur Return on Investment (ROI) di area ini” (Grant \& Anderson, 2002).

Beberapa penelitian sebelumnya menunjukkan adanya pengaruh antara CRM terhadap kinerja perusahaan. CRM meningkatkan kinerja organisasi melalui kegiatan seperti peningkatan pelanggan kepuasan dan kesetiaan, penjualan silang produk dan jasa 
menggunakan kata dari mulut ke mulut dan profitabilitas organisasi melalui pengiriman produk dan layanan yang lebih baik yang mengarah ke lebih banyak lagi keuntungan bagi perusahaan (Gathaiga, 2013). "Penerapan CRM yang efektif akan perpengaruh terhadap kinerja pemasaran dan kinerja keuangan yang terakumulasi sebagai kinerja perusahaan" (Capgemini, 2013).

\section{Pengertian Word of Mouth (WOM)}

Word-of-mouth communication, pada dasarnya adalah "pesan tentang produk atau jasa suatu perusahaan, ataupun tentang perusahaan itu sendiri, dalam bentuk komentar tentang kinerja produk, keramahan, kejujuran, kecepatan pelayanan dan hal lainnya yang dirasakan dan dialami oleh seseorang yang disampaikan kepada orang lain. Pesan yang disampaikan dapat berbentuk pesan yang sifatnya positif maupun negatif bergantung pada apa yang dirasakan oleh si pemberi pesan tersebut atas jasa yang ia konsumsi”(Ruhamak \& Rahayu, 2016).

Komunikasi dari mulut ke mulut (word of mouth communication) dapat diukur dengan indikator sebagai berikut: "Kemauan pelanggan dalam membicarakan hal-hal positif kualitas pelayanan perusahaan kepada orang lain,rekomendasi jasa perusahaan kepada orang lain, dorongan terhadap teman/relasi untuk melakukan pembelian terhadap jasa perusahaan” (Ronny \& Sunandar, 2007).

\section{Kinerja Perusahaan}

"Kinerja sebagai suatu keterkaitan antara variabel perilaku (processess), ouput dan outcomes (value added or impact)" (Mwita, 2000). "Suatu model yang terintegrasi dan terpadu yang menjelaskan hubungan antara perilaku kewirausahaan perusahaan dengan lingkungan, strategi, faktor internal perusahaan dan dengan kinerja perusahaan" (Covin \& Slevin, 1989).

"Pengukuran kinerja bisnis dapat dilakukan dengan menggabungkan dua faktor, yaitu; (1) pengukuran kinerja perusahaan dapat mengadopsi ukuran yang sudah ada, (2) pengukuran kinerja harus relevan sehingga perusahaan harus selalu melakukan perubahan setiap waktu" (Neely, 1999). Selain itu, "kinerja dapat diukur melalui kinerja keuangan, kepuasan pelanggan, proses internal dan pembelajaran serta pertumbuhan" (Tsang, Jardine, \& Kolodny, 1999). Menurut hasil penelitian lain, "kinerja suatu bisnis dapat 
diukur dari; tingkat penjualan, biaya penjualan, aset yang dimiliki, citra merek dan aset tetap yang dimiliki oleh perusahaan" (Bititci, Turner, \& Begemann, 2000).

Beberapa ahli mengungkapkan bahwa "ukuran kinerja perusahaan yang paling sering digunakan dalam penelitian empiris adalah kinerja keuangan (financial performance), kinerja operasional (operational performance), dan kinerja berbasis pasar (market-based performance)" (Jahanshahi, Rezaie, Nawaser, Ranjbar \& Pitamber, 2012).

\section{Hipotesis}

Hipotesis dalam penelitian ini yaitu

$\mathrm{H}_{1}$ : Customer Relationship Management (CRM) berpengaruh terhadap kinerja perusahaan.

$\mathrm{H}_{2}$ : Word of Mouth (WOM) berpengaruh terhadap kinerja perusahaan.

$\mathrm{H}_{3}$ : Customer Relationship Management dan Word of Mouth (WOM) secara simultan berpengaruh terhadap kinerja perusahaan.

\section{METODE PENELITIAN}

\section{Populasi dan Sampel}

Populasi dalam penelitian ini yaitu pelaku usaha mikro kecil menengah yang ada di Kota Kediri, jumlah UKM yang ada di Kota Kediri menurut data dari Dinas Koperasi dan UMKM Jawa Timur sejumlah 29.306. Sedangkan sampel penelitian ini sejumlah 100 UMKM diambil dengan teori pengambilan sampel dari slovin, dengan tingkat error $10 \%$.

\section{Tehnik Pengambilan Sampel}

Teknik penentuan sampel digunakan adalah purposive sampling dimana penelitian ini tidak dilakukan seluruh populasi tapi terfokus pada target. "Purposive Sampling artinya bahwa pengambilan sampel terbatas pada jenis orang tertentu yang dapat memberikan informasi yang diinginkan" (Sekaran, 2006).

\section{Analisis Data}

\section{Uji Validitas}

Uji validitas digunakan untuk mengukur sah atau valid tidaknya suatu kuesioner. "Suatu kuesioner dikatakan valid jika pertanyaan pada kuesioner mampu untuk mengungkapkan sesuatu yang akan diukur oleh kuesioner tersebut" (Ghozali,2005). 
"Uji validitas dilakukan dengan membandingkan nilai $\mathrm{r}$ hitung dengan $\mathrm{r}$ tabel untuk tingkat signifikasi 5 persen dari degree of freedom $(\mathrm{df})=\mathrm{n}-2$, dalam hal ini $\mathrm{n}$ adalah jumlah sampel. Jika $\mathrm{r}$ dihitung $>\mathrm{r}$ tabel maka pertanyaan atau indikator tersebut dinyatakan valid, demikian sebaliknya bila $r$ hitung $<r$ tabel maka pertanyaan atau indikator tersebut dinyatakan tidak valid" (Ghozali, 2005).

\section{Uji Reliabilitas}

Uji reliabilitas adalah alat untuk mengukur suatu kuesioner yang merupakan indikator dari variabel atau konstruk. "Suatu kuesioner dikatakan reliable atau handal jika jawaban seseorang terhadap pernyataan adalah konsisten atau stabil dari waktu ke waktu" (Ghozali, 2005). Pengukuran reliabilitas dilakukan dengan cara one shot atau pengukuran sekali saja dengan alat bantu SPSS uji statistik cronbach Alpha $(\alpha)$. "Suatu konstruk atau variabel dikatakan reliabel jika memberikan nilai Cronbach Alpha $(\alpha)>0,60$ " (Ghozali,2011:46), dan umumnya digunakan patokan sebagai berikut:

a. Reabilitas uji coba $\geq 0,60$ artinya, hasil uji coba memiliki reabilitas baik

b. Reabilitas uji coba $<0,60$ artinya, hasil uji coba memiliki reabilitas kurang baik

\section{Analisis Regresi Linier Berganda}

Regresi bertujuan untuk menguji hubungan pengaruh antara satu variabel terhadap variabel lain. "Variabel yang dipengaruhi disebut variabel tergantung atau dependen, sedangkan variabel yang mempengaruhi disebut variabel bebas atau variabel independen”. (Nugroho,2005).

Analisis Regreasi Linier Berganda : $Y=a+b_{1} X_{1}+b_{2} X_{2}+e$. Dalam analisis ini teknik mencari regresi berganda dengan menggunakan output program SPSS (statistical package for social sciences) pada tabel coefficients.

\section{Uji Hipotesis}

Dalam penelitian ini menggunakan uji t, untuk menguji variabel bebas secara satu persatu ada atau tidaknya pengaruh terhadap variabel terikat (Y). Dalam penelitian ini menggunakan uji f, untuk mengetahui seberapa besar pengaruh positif secara simultan yang signifikan antara $\mathrm{X}_{1}$ dan $\mathrm{X}_{2}$ terhadap $\mathrm{Y}$. 


\section{HASIL PENELITIAN DAN PEMBAHASAN}

Data penelitian ini didapatkan dan dikumpulkan dengan cara membagikan kuesioner secara langsung kepada responden yang berhasil ditemui. Kuesioner ini diperoleh dengan cara peneliti dengan menemui langsung responden dan memberikan kuesiner untuk di isi oleh para responden dengan jumlah 100 responden. Dari jenis usaha yang menjadi responden disini sebagian besar adalah industri pengolahan, perdagangan, transportasi dan jasa-jasa.

Hasil uji validitas pada penelitian ini menunjukkan bahwa hasil kuesioner dengan indikator dari Customer Relationship Manaegement (CRM), Word of Mouth (WOM) dan kinerja perusahaan semuanya dinyatakan valid. Sedangkan uji reliabelitas menunjukkan semua variabel mempunyai variabel Cronbach alpha yang cukup besar yaitu diatas 0,60 sehingga dapat dikatakan semua konsep pengukuran masing-masing variabel dari kuesioner adalah realibel sehingga untuk selanjutnya item-item pada masing-masing konsep variabel layak digunakan sebagai alat ukur.

Dalam pengolahan data dengan menggunakan regresi linier berganda, dilakukan beberapa tahapan untuk mencari hubungan antara variabel independen dengan variabel dependen melalui hubungan variabel Customer Relationship Management (CRM) dan Word Of Mouth (WOM) terhadap kinerja perusahaan. Dimana perhitungan ini menggunakan bantuan program SPSS diperoleh nilai koefisien regresi berganda yang mana muncul sebuah persamaan $\mathrm{Y}=-1.014+0,246 \mathrm{X}_{1}+0,368 \mathrm{X}_{2}+\mathrm{e}$.

Tabel 1. Koefisien Regresi

Coefficients $^{\mathrm{a}}$

\begin{tabular}{|c|c|c|c|c|c|c|}
\hline \multirow[b]{3}{*}{ Mod } & & \multicolumn{5}{|c|}{ Standardized } \\
\hline & & \multicolumn{2}{|c|}{ Unstandardized Coefficients } & \multirow{2}{*}{$\begin{array}{c}\text { Coefficients } \\
\text { Beta }\end{array}$} & \multirow[b]{2}{*}{$\mathrm{t}$} & \multirow[b]{2}{*}{ Sig. } \\
\hline & & $\mathrm{B}$ & Std. Error & & & \\
\hline \multirow[t]{3}{*}{1} & (Constant) & -1.014 & .763 & & -1.329 & .187 \\
\hline & $\mathrm{X} 1$ & .246 & .075 & .284 & 3.289 & .001 \\
\hline & $\mathrm{X} 2$ & .368 & .057 & .559 & 6.459 & .000 \\
\hline
\end{tabular}

a. Dependent Variable: $Y$

Sumber : Data primer diolah peneliti, 2018.

Dari persamaan tersebut diatas maka dapat diiterprestasikan bahwa, konstanta $\alpha=$ -1.014 artinya apabila tidak ada perubahan CRM dan Word Of Mouth (WOM), maka 
kinerja perusahaan akan meningkat sebesar -1.014 satuan. Jika CRM naik sebanyak satu satuan, kinerja perusahaan akan meningkat sebesar 0,246 satuan. Berikutnya jika Word Of Mouth naik sebanyak satu satuan, kinerja perusahaan akan meningkat sebesar 0,368 satuan.

Berdasarkan dari hasil uji t di atas maka dapat ditarik kesimpulan bahwa semua variabel yang terdiri dari variabel CRM dan variabel Word of Mouth (WOM) berpengaruh secara parsial terhadap kinerja perusahaan pada UMKM di Kota Kediri. Dan berpengaruh yang paling besar di tunjukan oleh variabel Word of Mouth (WOM). Hal ini menunjukkan bahwa $\mathrm{H}_{1}$ dan $\mathrm{H}_{2}$ diterima. Penelitian ini didukung dari penelitian sebelumnya dimana hasil penelitiannya menunjukkan bahwa CRM memiliki pengaruh terhadap kinerja perusahaan. Dan menyimpulkan bahwa penerapan CRM yang baik akan mampu meningkatkan kinerja perusahaan, baik dari kinerja keuangan maupun operasionalnya, .

\section{Tabel 2. Uji f}

ANOVA $^{\mathrm{a}}$

\begin{tabular}{llccccc}
\hline Model & & Sum of Squares & df & Mean Square & F & Sig. \\
\hline 1 & Regression & 304.360 & 2 & 152.180 & 75.379 & $.000^{\mathrm{b}}$ \\
& Residual & 195.830 & 97 & 2.019 & & \\
& Total & 500.190 & 99 & & & \\
\hline
\end{tabular}

a. Dependent Variable: $Y$

b. Predictors: (Constant), X2, X1

Sumber : Data primer diolah peneliti, 2018.

Untuk pengujian hipotesis berikutnya yaitu $\mathrm{H}_{3}$, dapat dilihat bahwa signifikan dari uji F untuk variabel bebas lebih kecil dari signifikan $\alpha(0,05)$. Hal ini menunjukkan bahwa $\mathrm{H}_{3}$ diterima. Jadi kedua variabel bebas yang terdiri dari CRM dan orientasi kewirausahaan mempunyai pengaruh secara simultan terhadap kinerja perusahaan.

\section{KESIMPULAN DAN SARAN}

\section{Kesimpulan}

Berdasarkan hasil pembahasan maka dapat disimpulkan :

1. Dari hasil pembahasan diatas menunjukkan bahwa secara parsial Customer Relationship Management (CRM) mempunyai pengaruh terhadap kinerja 
perusahaan. Apabila CRM diterapkan maka kinerja usaha pada usaha kecil menengah di Kota Kediri.

2. Hasil diatas menunjukkan bahwa secara parsial Word of Mouth (WOM) mempunyai pengaruh terhadap kinerja perusahaan. Hal ini dengan cara memperbaiki kualitas pelayanan kepada pelanggan dan calon pelanggan. Dengan kepuasan pelanggan tersebut menghasilkan komunikasi yang baik antara pelanggan dan calon pelanggan sehingga kinerja usaha dari UKM di Kota Kediri meningkat.

3. Hasil menunjukkan CRM dan WOM secara simultan berpengaruh signifikan terhadap kinerja perusahaan. Apabila semua usaha mikro kecil menengah di Kota Kediri menerapkan dan meningkatkan CRM dan WOM maka akan terjadi peningkatan kinerja perusahaan. Dan hal ini baik untuk bertahannya usaha tersebut.

\section{Saran}

Berdasarkan hasil penelitian, pembahasan dan keterbatasan penelitian, maka dapat dikemukakan saran-saran sebagai berikut:

1. Diharapkan keseluruhan usaha kecil menengah yang ada di Kota Kediri memahami tentang Customer Relationship Management (CRM) dan Word of Mouth (WOM). Apabila variabeltersebut benar-benar dipahami dan ditingkatkan akan membantu peningkatan kinerja usaha mikro kecil menengah di Kota Kediri

2. Penggunaan wadah pengenalan sebuah produk barang dan jasa yang ada di Kediri dan sekitarnya sebenarnya sudah ada, contohnya facebook dengan akun Kuliner Kediri Raya dan kampung UMKM Kediri. Akan tetapi pelaku UKM di Kota Kediri jarang menggunakan wadah tersebut untuk pengenalan sebuah produk dan jasa.

3. Dalam keterbatasan penelitian ini, diharapkan adanya penelitian baru selain variabel CRM dan WOM yang akan mampu mempengaruhi kinerja perusahaan. Dan mungkin penelitian ini juga dilakukan di daerah lain agar menemukan temuan baru yang akan membantu pengembangan usaha mikro kecil menengah

\section{DAFTAR PUSTAKA}

Bititci, U. S., Turner, Ut., \& Begemann, C. (2000). Dynamics of performance measurement systems. International Journal of Operations \& Production Management, 20(6), 692-704. https://doi.org/10.1108/01443570010321676 
Capgemini. (2013). Customer Relationship Management Next Generation ( CRM NG ). Dharma Ekonomi, 18(33), 1-12.

Covin, J. G., \& Slevin, D. P. (1989). Strategic management of small firms in hostile and benign enviroments. Strategic Management Journal, 10(1), 75-87. https://doi.org/10.1002/smj.4250100107

Gathaiga, A. M. (2013). Customer Relationship Management As a Strategy To Gain Competitive Advantage in the Banking Industry a Case Study of Kenya Commercial Bank in Kenya By United States International University.

Grant, G. B., \& Anderson, G. (2002). Technologies to Make IT Personal A Vision for Higher Education. Educase.

Mwita, J. I. (2000). Performance management model: A systems-based approach to public service quality. International Journal of Public Sector Management, 13(1), 19-37. https://doi.org/10.1108/09513550010334461

Neely, A. (1999). The performance measurment revolution: why now and what next? International Journal of Operations \& Production Management, 19(2), 205-228. https://doi.org/10.1108/01443579910247437

Ruhamak, M. D., \& Rahayu, B. (2016). Pengaruh Word Of Mouth Terhadap Purchase Intention Melalui Brand Image Pada Lembaga Kursus Bahasa Inggris Dynamic English Course Pare. Jurnal Ekonomi Universitas Kadiri, 1(2), 188-204.

Tsang, A. H. C., Jardine, A. K. S., \& Kolodny, H. (1999). Measuring maintenance performance: A holistic approach. International Journal of Operations and $\begin{array}{lll}\text { Production } \quad \text { Management, } & \text { 691-715), }\end{array}$ https://doi.org/10.1108/01443579910271674

Yosua, B., Suharyono, S., \& Yulianto, E. (2017). PENGARUH CUSTOMER RELATIONSHIP MANAGEMENT (CRM) TERHADAP KEPUASAN DAN LOYALITAS PELANGGAN (Survei pada Pelanggan GraPARI Telkomsel di Kota Malang). Jurnal Administrasi Bisnis, 46(1). 